\title{
1 Acoustic classification of coexisting taxa in a coastal ecosystem
}

3 Mei Sato* ${ }^{1}$, John K. Horne ${ }^{1}$, Sandra L. Parker-Stetter ${ }^{1}$, and Julie E. Keister ${ }^{2}$

4

$5{ }^{1}$ School of Aquatic and Fishery Sciences, University of Washington, Box 355020, Seattle, WA

6 98195-5020, USA

$7 \quad{ }^{2}$ School of Oceanography, University of Washington, Box 357940, Seattle, WA 98195-7940,

8 USA

9 * Corresponding author: meisato@uw.edu, Tel: (206) 221-5459

\section{Abstract}

13 Classifying coexisting taxa in a coastal ecosystem remains an analytic challenge due to the

14 difficulty in verifying species compositions within backscatter data. Multifrequency

15 measurements $(38,70,120,200 \mathrm{kHz})$ were combined with midwater trawls and zooplankton

16 MultiNet tows in Hood Canal, WA, to classify backscatter dominated by single fish species

17 (Pacific Herring, Pacific Hake) or major zooplankton taxa (euphausiids, copepods). Backscatter

18 was categorized into aggregations, single targets, and layers based on morphology.

19 Aggregations and single targets were identified in raw volume backscattering strength $\left(S_{v}\right)$, while

20 layers were classified using differences in mean volume backscattering strength $\left(\Delta \mathrm{MVBS}_{i-j}=\right.$

$21 \mathrm{MVBS}_{i}-\mathrm{MVBS}_{j}$, where $i$ and $j$ denote frequency in $\mathrm{kHz}$ ). Based on a subset of trawl-validated

22 in situ acoustic measurements, backscatter with $-16 \mathrm{~dB}<\Delta \mathrm{MVBS}_{200-38} \leq 2 \mathrm{~dB}$ were classified as

23 fish, and $2 \mathrm{~dB}<\Delta \mathrm{MVBS}_{200-38}<30 \mathrm{~dB}$ as zooplankton. Backscatter identified as fish were

24 further classified to hake when $\Delta \mathrm{MVBS}_{120-38}<-4.8 \mathrm{~dB}$, and herring when $\Delta \mathrm{MVBS}_{120-38} \geq-4.8$ 
$25 \mathrm{~dB}$. The classification method was evaluated using a second set of trawl-validated acoustic data, 26 resulting in classification accuracy of fish or zooplankton ranging from $95 \%$ to $100 \%$. At the

27 species level, misclassifications of herring and hake were both $\sim 13 \%$. Removal of aggregations

28 and single targets before calculating $\triangle \mathrm{MVBS}$ values minimized the possibility of mixed species

29 backscatter within layers. This classification technique provides an approach to separate

30 coexisting aggregations of dominant taxa which are common in mid- and low-latitude coastal

31 ecosystems.

32

33 Keywords

34 Acoustics; Classification; Pacific Herring; Pacific Hake; Zooplankton

35

36

37 1. Introduction

38 Active acoustics is increasingly used to study the abundance, distribution, and behavior of fish

39 and zooplankton communities (e.g., Greenlaw 1979, MacLennan and Holliday 1996, Sato et al.

40 2013). Using ships, moorings, or cabled observatories, acoustics provides continuous

41 measurements of organism densities at high spatial and temporal resolutions. Despite these

42 advantages over traditional net samples, species identification remains a major challenge when

43 using acoustics (Horne 2000). Multiple frequencies are commonly used to separate gas-bearing

44 from non-gas-bearing organisms, utilizing frequency-dependent backscatter characteristics (e.g., 45 Foote 1980, Holliday and Pieper 1980). Among various multifrequency classification methods, 
46 differencing the mean volume backscattering strength ( $\triangle \mathrm{MVBS}$ ) of two frequencies (Kang et al.

47 2002, Korneliussen and Ona 2003, Madureira et al. 1993) has been the most widely used.

48 Using $\triangle$ MVBS to categorize and identify aquatic organisms appears simple, yet its utility

49 and efficacy depend on the species composition, relative abundance, frequency-dependent

50 backscatter characteristics, and spatial overlap of species present. In mid- and low-latitude

51 coastal ecosystems, where coexisting aggregations of different taxa are common, classification

52 of acoustic data is challenging due to the difficulty in verifying species composition of various

53 backscatter types such as aggregations and layers. A combination of sampling gears is essential

54 to characterize mixed aggregations of fish and zooplankton, but logistical constraints often make

55 concurrent sampling difficult. As a result, $\triangle \mathrm{MVBS}$ values necessary for classification are often

56 not estimated due to the lack of ground-truthing. Alternatively, backscatter models could be

57 used to estimate $\triangle$ MVBS values if species compositions and length distributions are known, as

58 well as suitable backscatter models for the species of interests are available (e.g., Kang et al

59 2002). Due to the difficulties in satisfying all of these requirements, many studies acquiring

60 multifrequency acoustic data utilize single frequencies to estimate distributions and densities of

61 target species (e.g., Mackas et al. 1997, Parker-Stetter et al. 2008). Even though $\triangle$ MVBS is a

62 well-established classification method, the sequence of steps to classify coexisting species has

63 not been described in detail.

64 This study demonstrates an approach to classify coexisting dominant taxa, using data

65 collected in a temperate fjord within existing analytic techniques of fish school and single target

66 detections. The objective was to establish an acoustic classification technique that separates fish

67 from zooplankton, and then separates dominant fish species. In this case, zooplankton, Pacific

68 Herring (Clupea pallasi), and Pacific Hake (Merluccius productus). 


\section{2. Material and methods}

\section{2.1. Data collection}

73 Data collected in Hood Canal, WA, were used as a case study for the development of the

74 classification technique. Surveys were conducted during June, July, August, September, and

75 October in 2012 and 2013. CTD (conductivity, temperature, depth) profiles, acoustic

76 measurements, and net samples were collected by two vessels during day and night over four

77 days at four locations within Hood Canal to characterize densities and distributions of dominant

78 taxa and oceanographic properties. Acoustic measurements and midwater trawls were conducted

79 from the $R / V$ Centennial. Zooplankton sampling and CTD profiles were conducted from the $R / V$

80 Clifford A. Barnes.

81

$82 \quad 2.1 .1$. Acoustic data collection

83 Acoustic backscatter data were collected using Simrad EK60 split-beam echosounders operating

84 at $38,70,120$, and $200 \mathrm{kHz}$. The transducers were deployed $2 \mathrm{~m}$ below the surface on a rigid

85 pole mounted to the vessel's starboard side. The centers of each transducer were no more than

$8647 \mathrm{~cm}$ apart to maximize spatial overlap of the beams. The 38-kHz transducer had a beam width

87 of $12^{\circ}$ (between half power points), while the 70,120 , and $200 \mathrm{kHz}$ transducers all had beam

88 widths of $7^{\circ}$. Echosounders operated at $0.5-2$ pings $\mathrm{s}^{-1}$ with a pulse duration of $512 \mu \mathrm{s}$.

89 Backscattered acoustic signals were digitized into 10-cm depth bins. All echosounders were

90 calibrated using a 38.1-mm diameter tungsten carbide sphere (Demer et al. 20105). Vessel speed

91 during acoustic surveys was $5-6$ knots, decreasing to $2-3$ knots during midwater trawling. 


\section{2.1.2. Biological samples}

94 Acoustic backscatter including layers and fish aggregations detected by the echosounders were 95 sampled with a midwater trawl or zooplankton nets to estimate species composition and length

96 distributions. The sampling gear used depended on the suspected identity of the organisms.

98 Midwater trawling: Aggregations and layers of fish and large invertebrates were sampled with a

99 Marinovich midwater trawl (6 66 m opening) fitted with a 3.2-mm knotless liner in the codend.

100 The fishing depth of each trawl was targeted to sample regions of high acoustic backscatter, with

101 trawl depth being monitored and directed using a real-time pressure sensor (PI50; Kongsberg

102 Maritime) attached to the headrope. Trawl duration was typically $\sim 8$ min, but varied from $3-$

10333 min depending on the observed density of backscatter. Since the trawl did not have a closing

104 mechanism, the catch could result from the depths shallower than the target fishing depth.

105 Catches were identified, enumerated, weighed, and a sample of each species was measured for 106 length.

107

108 Zooplankton sampling: Zooplankton were sampled with a MultiNet system (Hydro-Bios)

109 configured with five, opening-closing $335-\mu \mathrm{m}$ mesh nets with a $0.25-\mathrm{m}^{2}$ mouth opening, double

110 flowmeters, and a CTD sensor. Depth-stratified oblique tows were conducted at a vessel speed

111 of $2-4$ knots to target backscatter layers observed by the echosounders. All MultiNet tows were

112 conducted within the acoustic survey areas less than 2 hours from the acoustic measurements to

113 minimize temporal mismatch between net sampling and acoustic measurements. MultiNet tow

114 duration within a targeted layer varied from $1-7$ min depending on the vertical thickness of the 
115 layers. Samples were fixed in 5\% formalin buffered with sodium borate. In the laboratory, a

116 subsample from each zooplankton tow was identified to taxa, counted, and measured for length

117 using the silhouette method (WHOI Silhouette DIGITIZER v 1.1; Davis and Wiebe 1985, Little

118 and Copley 2003). Euphausiid length was measured from the posterior base of the eye stalk to

119 the end of the sixth abdominal segment [Standard Length 3 in Mauchline (1980), as cited by

120 Ashjian et al. (2004)]. Total body length was measured for all other zooplankton taxa. Biomass

121 (wet weight) was estimated based on length measurements using the equations adapted from

122 previous studies (Lavaniegos and Ohman 2007, Webber and Roff 1995, Williams and Robins

123 1979).

124

125 2.1.3. Oceanographic data

126 To characterize vertical and seasonal variability of water properties, at least 8 CTD (SBE

127 911plus; Sea-Bird Electronics) profiles were collected during each monthly field survey.

128 Monthly averages of CTD downcasts through the water column were used to estimate sound

129 speed and absorption coefficients, which were used to calculate volume backscattering strength

$130\left(S_{v} ; \mathrm{dB}\right.$ re $\left.1 \mathrm{~m}^{-1}\right)$ from acoustic measurements.

131

$132 \quad$ 2.2. Data analysis

133 2.2.1. Acoustic data processing

134 Acoustic data were processed using Echoview (version 5.4; Echoview Software Pty Ltd). Vessel

135 noise estimated during passive acoustic measurements (38 kHz: $-152 \mathrm{~dB}, 70 \mathrm{kHz}:-160 \mathrm{~dB}, 120$

$136 \mathrm{kHz}:-149 \mathrm{~dB}, 200 \mathrm{kHz}:-145 \mathrm{~dB}$ ) was removed by linear subtraction. Data shallower than $5 \mathrm{~m}$

137 were removed from analyses to eliminate near-field transducer effects and reduce backscatter

138 from surface bubbles. The sounder-detected bottom was visually inspected, corrected if 
necessary, and data within $0.5 \mathrm{~m}$ of the bottom were removed from analyses.

140 The acoustic data at each frequency were categorized into (i) aggregations (i.e., acoustic

141 backscatter with discrete, closed edges), (ii) single targets (i.e., targets at densities lower than one

142 per sampling volume), and (iii) layers (i.e., acoustic backscatter without discrete, closed edges),

143 based on their morphologies (summarized in Fig. 1: 'Raw data' panel) as described below.

144 Acoustic data categorized as aggregations and single targets were classified as 'fish'. Two sets

145 of parameters (Table 1) were applied to detect different aggregation-size classes of fish in the 38

$146 \mathrm{kHz}$ raw data, using the school detection module in Echoview (Barange 1994, Coetzee 2000):

147 'herring aggregations' (Fig. 1; $S_{v}$ herring aggregation confirmed by midwater trawls), then 'other

148 aggregations' $\left(S_{v}\right.$ other aggregation). Detected aggregations were visually inspected to avoid false

149 detections such as layers. If a suspected aggregation was consistent with the acoustic

150 characteristics of a fish aggregation but not detected by the Echoview's school detection module,

151 then it was manually defined as an aggregation using Echoview's region tool. Acoustic data not

152 categorized as aggregations $\left(S_{v \text { non-aggregation }}\right)$ were then used to identify echoes from single targets

$153\left(S_{v}\right.$ single target $)$ using the single target detection parameters (Table 2) following Benoit-Bird et al.

154 (2009). Single target detection was used as a tool to detect fish echoes, but target strengths (TS)

155 were not estimated. The order of the categorization (i.e., detection of aggregations, then single

156 target detection) avoided false detections of single targets within aggregations. Detected single

157 targets were excluded from the data at each frequency, leaving layers $\left(S_{v}\right.$ non-single target). To

158 decrease natural stochastic variability in acoustic backscatter, $S_{v}$ data within each category were 159 averaged into 20-ping horizontal by 2-m vertical bins (MVBS non-single target), which corresponded

160 to a horizontal distance of $15 \mathrm{~m}$ with $2 \mathrm{~Hz}$ sampling (62 m with $0.5 \mathrm{~Hz}$ sampling) at trawling 
161 speed of 3 knots, and $31 \mathrm{~m}$ with $2 \mathrm{~Hz}$ sampling (123 m with $0.5 \mathrm{~Hz}$ sampling) at acoustic survey

162 speed of 6 knots. MVBS non-single target data were treated as layers and classified to dominant taxa.

164 2.2.2. Selection of representative samples for classification

165 To classify acoustic backscatter layers into taxa, we examined acoustic backscatter data collected

166 during net sampling. When net catches indicated a dominance of a single taxon, regardless of

167 the time of sampling, the corresponding periods of acoustic data were isolated, analyzed, and

168 designated as representative samples. These representative samples were used to determine the

169 frequency pairs and $\triangle \mathrm{MVBS}$ values for separating taxa. An implicit assumption in this

170 procedure is that each cell of the representative samples contains a single fish species (either

171 herring or hake) or zooplankton.

172

173 Fish: A total of 149 trawls were screened to select representative samples. First, any trawl catch

174 composition dominated by a single species (herring: $>80 \%$ by number and $>60 \%$ by weight,

175 hake: $>60 \%$ by number and weight) was identified as a candidate trawl. These criteria were

176 used to select trawl samples dominated by a single species, and ensured more than one sample

177 for each species. Second, acoustic data collected concurrently with candidate trawls were

178 examined to select layers, and to exclude aggregations and single targets. Acoustic data

179 corresponding to the area of the candidate trawl were defined horizontally by a time interval

180 where the trawl had stabilized at the target fishing depth, and vertically by extending $12 \mathrm{~m}$ below

181 the trawl headrope. For one trawl dominated by herring, the vertical depth was limited to $6 \mathrm{~m}$

182 below the headrope to exclude a non-herring acoustic layer having characteristics of low $S_{v}$

183 values with diffuse aggregations. To account for the spatial difference between the transducers 
184 and the midwater trawl, horizontal offset between the transducers mounted on the vessel and the

185 trawl was corrected based on deployed trawl wire lengths and trawled depth for each trawl.

186 Effect of vessel speed on the horizontal offset is unlikely, because trawl wire lengths were fixed

187 during the trawls and the headrope depth was maintained by adjusting ship speed. Third,

188 echograms were visually examined to ensure that there were no obvious signs of another taxon,

189 such as backscatter layers from zooplankton. Acoustic data passing these three criteria were

190 designated as representative samples and assigned to the taxon dominating the trawl catch for

191 further analysis.

192

193 Zooplankton: A total of 79 net samples were examined to select representative samples in which

194 euphausiids and copepods dominated backscatter measurements. First, net samples dominated

195 by euphausiids and copepods for more than $80 \%$ by wet weight were identified as candidate

196 samples. Net samples were constrained to avoid including strong acoustic backscatterers such as

197 thecosome pteropods (Limacina helicina) and gastropods whose densities were greater than 5

198 individuals (ind.) $\mathrm{m}^{-3}$. Acoustic data corresponding to candidate samples were identified based

199 on GPS locations and depths sampled by the MultiNet. Second, acoustic data collected near

200 candidate samples were limited to contain only echoes from zooplankton by removing co-located

201 fish aggregations and single targets from zooplankton backscatter layers (see section 2.2.1). To

202 ensure that only echoes from zooplankton were included, acoustic data dominated by fish

203 aggregations and single targets, or diffuse layers of zooplankton were excluded from candidate

204 samples based on visual inspections. Acoustic data passing these criteria were designated as

205 representative zooplankton samples for further analysis.

206 
208 Acoustic backscatter frequency differences for all possible frequency pairs $\left(\Delta \mathrm{MVBS}_{i-j}=\mathrm{MVBS}_{i}\right.$

$209-\mathrm{MVBS}_{j}$, where $i$ and $j$ denote frequency in $\mathrm{kHz}$ ) were calculated for each averaged cell of the 210 representative samples. The difference in logarithmic domains is equivalent to the ratio of $S_{v}$ in

211 corresponding linear units $\left(s_{v} ; \mathrm{m}^{2} \mathrm{~m}^{-3}\right)$. Pairwise frequency difference values were compiled, and

212 the mean and standard deviation at each frequency pair were calculated for each taxon. To

213 minimize the effects of background noise in each cell, only cells where MVBS non-single target

214 values greater than $-78 \mathrm{~dB}$ and signal-to-noise ratios equal to or greater than $10 \mathrm{~dB}$ for at least

215 one of the frequencies in the pair were used for further analysis. The threshold was determined

216 by calculating nautical area scattering coefficient (NASC; $\mathrm{m}^{2} \mathrm{nmi}^{-2}$ ) of the representative

217 samples at thresholds ranging from -90 to $-42 \mathrm{~dB}$ in $6 \mathrm{~dB}$ steps, following Jech and Michaels

218 (2006). The final choice of the $-78 \mathrm{~dB}$ threshold was chosen to maximize total NASC values,

219 where no changes in NASC were observed when lower than -78 dB thresholds were applied.

220 Combinations of frequency pairs and values for separating representative samples of fish

221 (MVBS $\left._{\text {fish }}\right)$ vs. zooplankton $\left(\mathrm{MVBS}_{\text {zooplankton}}\right)$ vs. other $\left(\mathrm{MVBS}_{\text {other }}\right)$, and herring $\left(\mathrm{MVBS}_{\text {herring }}\right.$

222 layers $)$ vs. hake ( $\left.\mathrm{MVBS}_{\text {hake layers }}\right)$ were determined by selecting the frequency pairs having

223 minimum overlap in $\triangle$ MVBS histograms. Total backscatter attributed to fish, including

224 aggregations, single targets, and layers, was estimated using: $\mathrm{MVBS}_{\mathrm{fish} \text { all }}=\mathrm{MVBS}_{\text {all }}-$

$225 \mathrm{MVBS}_{\text {zooplankton }}-\mathrm{MVBS}_{\text {other. }}$ Acoustic backscatter attributed to herring was estimated using:

$226 \mathrm{MVBS}_{\text {herring }}=\mathrm{MVBS}_{\text {herring layers }}+\mathrm{MVBS}_{\text {herring aggregations. Other aggregations and single targets }}$

227 were not classified to species because of the difficulty in ground-truthing and applying the 228 classification method to small aggregations. 
231 To evaluate accuracy of the classification method, net samples dominated by single fish species

232 or major zooplankton taxa and not used as representative samples were selected as validation

233 samples. Unlike representative samples, which were limited to layers, validation samples were

234 selected regardless of acoustic morphology. For fish, trawl catches dominated by single fish

235 species (herring: $>90 \%$ by number and $>60 \%$ by weight, hake: $>60 \%$ by number and $>40 \%$ by

236 weight) were identified as candidate validation trawls. For zooplankton, net samples with more

237 than $80 \%$ wet weight of euphausiids and copepods, and less than 5 ind. $\mathrm{m}^{-3}$ of thecosome

238 pteropods and gastropods were identified as candidate validation trawls. Acoustic backscatter

239 data corresponding to the candidate trawls were defined as described in section 2.2.2 and

240 echograms were visually examined to ensure that there were no obvious signs of another taxon,

241 such as zooplankton backscatter layers in fish validations samples. For fish validation,

242 echograms were also examined to ensure that no significant backscatter was present shallower

243 the trawled area so that the trawl catches were representative of the region identified on the

244 echogram. Acoustic data passing these criteria were designated as validation samples.

245 The classification method outlined in Fig. 1 was applied to the validation samples. We

246 assumed that a single taxon dominated the validation samples and that any MVBS classified to a

247 taxon other than the corresponding dominant trawl-caught taxon was a misclassification. For

248 fish samples, percentages of NASC values classified within each category were estimated using

$24938 \mathrm{kHz}$ data. For zooplankton samples, percentages of NASC values classified to fish,

250 zooplankton, and other were estimated using $200 \mathrm{kHz}$ data. NASC values of aggregations and

251 single targets were not included, because fish could not be captured by the MultiNet and

252 therefore catch compositions were not representative of fish. 


\section{3. Results and Discussion}

256 3.1. Species composition

257 Midwater trawling: Herring and hake were the dominant fish species and constituted $62 \%$ of

258 midwater trawl catches by number in 2012 and 52\% in 2013. Jellyfish (Cyanea capillata,

259 Phacellophora camtschatica, Aequorea victoria, Aurelia aurita) were also abundant constituting

$26034 \%$ of the trawl catches by number in 2012 and $40 \%$ in 2013 , with peak abundances in June and

261 decreased through fall. Since the decline in jellyfish abundance corresponded to the

262 disappearance of near-surface backscatter layers at $38 \mathrm{kHz}$ which were present earlier in the

263 season, we attributed the high density of jellyfish to incidental bycatch from surface layers.

265 Zooplankton sampling: Euphausiids, copepods, amphipods, decapods, chaetognaths, and crab

266 zoea accounted for most of the zooplankton collected in the acoustic backscatter layers.

267 Euphausiids (mostly Euphausia pacifica) and copepods were dominant acoustic backscatterers, 268 with their abundance often exceeding $70 \%$ of the total zooplankton by wet weight (range: 4 269 100\%). Major copepod species in Hood Canal are Metridia pacifica, Paracalanus parvus,

270 Pseudocalanus spp., Oithona similis, and Calanus pacificus (Keister and Tuttle 2013). High

271 densities of thecosome pteropods (Limacina helicina) were observed in 3 out of 79 samples at

272 densities greater than 80 ind. $\mathrm{m}^{-3}$. Another acoustically important taxon is siphonophores that

273 contain gas-filled pneumatophores (e.g., Nanomia bijuga), however no pneumatophore-bearing

274 siphonophores were captured by the MultiNet in this study. Since intact siphonophores cannot

275 be captured using MultiNet tows, Herrmann (2014) counted the number of nectophores 
276 (mouthless, pulsating swimming bell) of $N$. bijuga in the samples which resulted in densities of 0 $277-0.3 \mathrm{~m}^{-3}$.

279 3.2. Representative samples for classification

280 Acoustic data from 5 trawls were designated as representative samples of herring, with their

281 catch composition ranging from $91 \%$ to $99 \%$ by number and $63 \%$ to $96 \%$ by weight. For hake,

282 acoustic data from 2 trawls were selected with their catch composition comprising $68 \%$ and $95 \%$

283 by number, and $61 \%$ and $80 \%$ by weight. The lower percentage of hake in catch composition by

284 number was attributed to the presence of herring schools above the targeted layer, resulting in the

285 contamination of trawl catches. Fork lengths of the fish caught in trawls selected as

286 representative samples varied between 14.7 (mean) $\pm 4.0 \mathrm{~cm}$ (standard deviation) and $17.5 \pm 1.1$

$287 \mathrm{~cm}$ for herring $(n=100-150$ within trawls $)$, and $19.0 \pm 2.2 \mathrm{~cm}$ and $20.6 \pm 2.9 \mathrm{~cm}$ for hake $(n=$ $288100-101)$

289 Acoustic data from 10 net tows were selected as representative samples of zooplankton, 290 with catch composition of euphausiids and copepods ranging from $81 \%$ to $96 \%$ by wet weight.

291 Lengths of zooplankton in the tows selected as representative samples ranged from $5.9 \pm 1.9 \mathrm{~mm}$

292 to $10.5 \pm 2.3 \mathrm{~mm}$ for euphausiids ( $n=89-457$ within tows), and $1.3 \pm 0.4 \mathrm{~mm}$ to $1.6 \pm 0.5 \mathrm{~mm}$ 293 for copepods $(n=220-538)$.

295 3.3. Classification of the dominant taxa

$296 \triangle$ MVBS values of representative samples differed among taxa at some of the acoustic frequency

297 pairs (Table 3). Backscatter layers dominated by zooplankton had consistently higher $\triangle \mathrm{MVBS}$

298 values than those of herring and hake, allowing separation of zooplankton and fish. This 
separation was greatest at $\Delta \mathrm{MVBS}_{200-38}$ (Fig. 2a), with $-16 \mathrm{~dB}<\Delta \mathrm{MVBS}_{200-38} \leq 2 \mathrm{~dB}$ used to

300 classify fish, $2 \mathrm{~dB}<\Delta \mathrm{MVBS}_{200-38}<30 \mathrm{~dB}$ used to classify zooplankton, and $\Delta \mathrm{MVBS}_{200-38} \leq-16$

$301 \mathrm{~dB}$ or $\triangle \mathrm{MVBS}_{200-38} \geq 30 \mathrm{~dB}$ used to classify other taxa (Fig. 1). Using these thresholds,

302 zooplankton would be misclassified as fish in $0.3 \%$ of the samples, and there was no

303 misclassification of fish as zooplankton. $\triangle$ MVBS values of herring and hake overlapped in most

304 of the frequency pairs. Overlap of the two distributions was minimized at $\Delta \mathrm{MVBS}_{120-38}$ (Fig.

305 2b), indicating the possibility to separate these taxa with minimal misclassification in the overlap

306 zone. By taking the mid-point of the $\Delta \mathrm{MVBS}_{120-38}$ mean values, acoustic backscatter with

$307 \Delta \mathrm{MVBS}_{120-38}<-4.8 \mathrm{~dB}$ was classified as hake layers, and $\triangle \mathrm{MVBS}_{120-38} \geq-4.8 \mathrm{~dB}$ as herring

308 layers (Fig. 1). This threshold would result in a misclassification of herring as hake in $12.5 \%$ of

309 the samples, and hake as herring in $13.7 \%$ of the samples. Misclassification could also be due to

310 the size of layers relative to the cell size. When layers extend over or not completely include a

311 boundary cell, there is equal probability of any portion of a layer that overlaps with an adjacent

312 cell to be misclassified as either species. However, this alternate misclassification should

313 average out. In addition, layer edges typically have weak backscatter values and are not

314 expected to heavily contribute to the misclassification.

315 Acoustic classification using two frequencies has been widely used to distinguish

316 zooplankton from fish. In Hood Canal, zooplankton exhibited a strong increase in backscatter

317 strength with frequency, distinct from the fish taxa, and consistent with previous studies (e.g., De

318 Robertis et al. 2010, Madureira et al. 1993). Using $\Delta \mathrm{MVBS}_{120-38}$ to separate hake from

319 euphausiids was previously done by McKelvey and Wilson (2006) for the same species off the

320 west coasts of U.S. and Canada. Their mean $\triangle \mathrm{MVBS}_{120-38}$ for hake matched the value

321 independently estimated in this study. The mean $\triangle \mathrm{MVBS}_{120-38}$ value for herring was similar to 
322 the one reported by Edwards et al. (1984) for mixed herring and sprat aggregations, which

323 resulted in the mean $\triangle \mathrm{MVBS}_{120-38}$ of $-2.05 \mathrm{~dB}$ based on TS values.

324 A separation of peaks in $\triangle \mathrm{MVBS}_{120-38}$ was observed between herring and hake.

325 Differences in their $\triangle \mathrm{MVBS}$ values could be attributed to differences in animal length

326 distributions, swimbladder structure and morphology, swimming angles, or combinations of

327 these factors. Since length distributions of herring and hake overlapped greatly, it is unlikely

328 that lengths contribute to the observed $\triangle$ MVBS differences of the two species. Swimbladders

329 have been identified as the primary cause of acoustic backscatter in fish, accounting for as much

330 as $90-95 \%$ of the reflected energy (Clay and Horne 1994, Foote 1980). Herring are

331 physostomous (Blaxter et al. 1979) inflating swimbladders by 'gulping' air at the sea surface

332 (Brawn 1962), while hake are physoclistous regulating swimbladder volume through blood

333 capillaries. Pressure effects on physoclists are less important than on physostomes, because

334 swimbladder volumes can be adjusted as fish alter depth. Swimbladder morphology also differs

335 between these two species. For individuals with similar lengths, swimbladder area and volume

336 of herring are more than double that of hake (Gauthier and Horne 2004, Henderson and Horne

337 2007). Since acoustic backscatter intensity is a function of swimbladder cross-sectional area and

338 shape at high frequencies (Ona 1990), differences in morphological characteristics can result in a

339 difference in $\triangle \mathrm{MVBS}$. Orientation of the fish also affects the amount of energy reflected by fish

340 (Horne and Clay 1998, Ona 2001), causing subsequent changes in $\triangle$ MVBS values due to

341 differences in backscatter between two frequencies (Kang et al. 2002).

343 3.4. Evaluation of the classification method

344 Classification of hake- and zooplankton-dominated acoustic backscatter data, confirmed by 
345 midwater trawl and MultiNet samples, was illustrated in Fig. 1. In the example, a thick layer

346 near the bottom resulted in high backscatter at $38 \mathrm{kHz}$, while strong backscatter layers at mid-

347 depths were observed at 120 and $200 \mathrm{kHz}$. Using $\Delta \mathrm{MVBS}_{200-38}$, the backscatter layer located

348 near the bottom was classified as fish, and the one in the middle of the water column

349 zooplankton. No cells were classified as the other group in this example. Acoustic backscatter

350 classified as fish was further divided into herring and hake using $\triangle \mathrm{MVBS}_{120-38}$. Visual

351 assessment of the classified echograms indicated that the identification of hake and zooplankton

352 was consistent with expectations based on net samples. There was some misclassification of the

353 near-bottom hake layer as herring. Weak backscatter layers above the hake layer were classified

354 as herring, but we did not have trawl samples to verify them.

355 To quantitatively evaluate the classification method, validation samples were chosen

356 (separately from representative samples) based on midwater trawl and MultiNet samples.

357 Acoustic backscatter data from 6 trawls were selected as validation samples for herring, with

358 catch composition ranging from $95 \%$ to $100 \%$ by number and $65 \%$ to $94 \%$ by weight. For hake,

359 acoustic data from 2 trawls were selected with catch composition of $77 \%$ and $87 \%$ by number,

360 and $46 \%$ and $85 \%$ by weight. Fork lengths of fish in validation trawls varied between $9.6 \pm 0.9$

$361 \mathrm{~cm}$ and $17.8 \pm 1.5 \mathrm{~cm}$ for herring $(n=100-101)$, and $16.5 \pm 12.5 \mathrm{~cm}$ and $23.8 \pm 8.9 \mathrm{~cm}$ for hake

$362(n=115-200)$. Acoustic backscatter data from 3 net samples were selected as validation

363 samples of zooplankton, with catch composition of euphausiids and copepods ranging from $84 \%$

364 to $100 \%$ by wet weight. Lengths of zooplankton in the tows selected as validation samples

365 ranged from $8.2 \pm 1.4 \mathrm{~mm}$ to $11.6 \pm 2.9 \mathrm{~mm}$ for euphausiids $(n=208-315)$, and $1.4 \pm 0.4 \mathrm{~mm}$

366 to $1.4 \pm 0.5 \mathrm{~mm}$ for copepods $(n=67-123)$.

367 The ability of our method to accurately classify acoustic backscatter was evaluated by 
368 classifying validation samples. Within acoustic backscatter samples of herring confirmed by 369 trawls, $99.9 \%$ of the NASC were classified as fish, and $0.1 \%$ as zooplankton. At the species

370 level, $13.8 \%$ were misclassified as hake. Similarly, validation samples of hake showed that

$37199.7 \%$ of the NASC was classified as fish, with misclassification of $0.3 \%$ as zooplankton and

$37214.1 \%$ as herring. For zooplankton validation samples, $95.3 \%$ of the NASC was classified as

373 zooplankton with $4.7 \%$ misclassified as fish. None of the acoustic backscatter was classified as

374 other in any of the validation samples. These misclassification rates were similar to those

375 estimated based on overlap in curves of the $\triangle \mathrm{MVBS}$ histograms (Fig. 2). Backscatter

376 contributions of unclassified categories (i.e., other aggregation and single target) varied from 5\%

377 to $48 \%$, depending on the morphologies of fish backscatter contained in the validation samples.

378 Due to their potentially high contributions to the total NASC values, classification of these

379 categories to species level using nets will be necessary for accurately estimating herring and hake 380 abundance.

382 3.5. Limitations of the classification method

383 The classification method proposed in this study makes several assumptions: (i) each analytic

384 cell contains a single taxon, (ii) herring, hake, zooplankton, and other are the only categories of 385 acoustic backscatter, and (iii) scattering properties and $\triangle \mathrm{MVBS}$ of taxa do not change

386 seasonally. These assumptions were also used in other $\triangle$ MVBS studies (e.g., De Robertis et al. 387 2010, Jech and Michaels 2006, Kang et al. 2002).

388 Analytic cell size affects variability of $\triangle$ MVBS values and potentially violates the 389 assumption that backscatter in each cell is dominated by a single taxon. The choice of cell size 390 has varied among previous studies, depending on scales of aggregations, sampling rate of 
391 acoustics, and ship speed. The cell size used in this study was within the range used in previous

392 studies [e.g., $7-24 \mathrm{~m}$ horizontal by $5 \mathrm{~m}$ vertical; De Robertis et al. (2010), $185 \mathrm{~m}$ horizontal by

$3935 \mathrm{~m}$ vertical; McKelvey and Wilson (2006)]. We also minimized the possibility of mixed species

394 backscatter within a cell by removing aggregations and single targets before calculating $\triangle$ MVBS

395 values. However, if a cell contained both zooplankton and fish within layers, then the cell was

396 classified as fish, resulting in a lower abundance of zooplankton. Potential mixed-species cells

397 are expected to occur at the edge of layers where zooplankton and fish can be co-located.

398 Identifying the appropriate frequency pairs for frequency differencing is challenging for

399 successful classification of fish and zooplankton. Both the choice of frequency pairs and

400 corresponding $\triangle \mathrm{MVBS}$ values influence the effectiveness of the method. At our study site,

401 jellyfish were a significant part of trawl catches during June and July, but were not included as

402 classification categories. Acoustic backscatter features of jellyfish can be similar to those of fish

403 (Purcell et al. 2000), and the reported $\Delta \mathrm{MVBS}_{120-38}$ values of $-3.3--2.2 \mathrm{~dB}$ (Brierley et al. 2001)

404 are very similar to those used for herring in this study. Using the classification method proposed

405 here, jellyfish would likely be misclassified as fish, specifically herring. Inclusion of additional

406 information, such as location in the water column, may help improve classification, but there

407 would still be vertical overlap with other categories due to diel vertical movement of some

408 jellyfish (Moriarty et al. 2012).

409 Seasonal changes in fish length and body composition may affect backscatter properties

410 of organisms, and resulting $\triangle$ MVBS values. In this study, herring and hake juveniles were

411 caught in August through October, but potential changes in fish length due to growth were not

412 reflected in the trawl catches due to selectivity of the trawl (McClatchie et al. 2000). TS

413 generally increases with increasing length, but $\triangle \mathrm{MVBS}_{120-38}$ of herring based on theoretical 
414 predictions varies between $-3 \mathrm{~dB}$ and $-9 \mathrm{~dB}$ without any correlation with fish length (Gauthier

415 and Horne 2004). Since the separation of peaks in $\triangle$ MVBS values is essential to classify taxa of

416 interest, seasonal changes in $\triangle$ MVBS may potentially impact the efficacy of the classification.

417 Body composition may change seasonally through growth and gonad production, which affects

418 body density and consequently TS due to the changes in backscatter properties and/or

419 swimbladder volume (Ona 1990). These changes potentially affect $\triangle \mathrm{MVBS}$ depending on

420 relative changes in the backscatter of any frequency pair.

421

422

\section{4. Conclusion}

424 Species classification of acoustic data is an ongoing challenge in aquatic environments, including 425 coastal ecosystems where several species may co-exist. Increased spatial overlap among taxa,

426 which is a common feature in mid- and low-latitude ecosystems, makes classification more

427 difficult. In this study, we demonstrated an empirical approach to classify acoustic backscatter

428 of dominant, coexisting taxa. Initial identification and separation of fish aggregations and single

429 targets from the remaining backscatter was necessary to successfully separate fish from

430 zooplankton. By filtering backscatter components and then frequency differencing in a defined

431 sequence, the complexity of aquatic community compositions that can be categorized using

432 multifrequency acoustic data increases. The procedure developed in this study focused on two

433 particular fish species and dominant zooplankton taxa; adaptation to other ecosystems will likely

434 require modification of the frequency pairs and $\triangle$ MVBS values used for separation. 


\section{Acknowledgements}

438 We thank the crew of the $R / V$ Centennial and $R / V$ Clifford A. Barnes for field support; $\mathrm{T}$.

439 Essington, J. Nomura, A. Winans, P. Moriarty, L. Tuttle, H. Froehlich, S. Hennessey, and L.

440 Raatikainen (University of Washington) assisted in the field; B. Herrmann (University of

441 Washington) assisted in taxonomic identification of zooplankton. This work was funded by the

442 National Science Foundation grant OCE-1154648AM001 to T. Essington, J.K. Horne, J.E.

443 Keister, and S.L. Parker-Stetter.

444 


\section{References}

446 Ashjian, C.J., Rosenwaks, G.A., Wiebe, P.H., Davis, C.S., Gallager, S.M., Copley, N.J., Lawson, G.L., Alatalo, P. 2004. Distribution of zooplankton on the continental shelf off Marguerite Bay, Antarctic Peninsula, during Austral Fall and Winter, 2001. Deep-Sea Res. II 51, 2073-2098.

Barange, M. 1994. Acoustic identification, classification and structure of biological patchiness

\section{3}

454

455

on the edge of the Agulhas Bank and its relation to frontal features. S. Afr. J. Mar. Sci. $14,333-347$.

Benoit-Bird, K.J., Cowles, T.J., Wingard, C.E. 2009. Edge gradients provide evidence of ecological interactions in planktonic thin layers. Limnol. Oceanogr. 54, 1382-1392.

Blaxter, J.H.S., Denton, E.J., Gray, J.A.B. 1979. The herring swimbladder as a gas reservoir for the acoustico-lateralis system. J. Mar. Biol. Assoc. U. K. 59, 1-10.

Brawn, V.M. 1962. Physical properties and hydrostatic function of the swimbladder of herring (Clupea harengus L.). J. Fish. Res. Board Can. 19, 635-656.

Brierley, A.S., Axelsen, B.R., Buecher, E., Sparks, C.A.J., Boyer, H., Gibbons, M.J. 2001. Acoustic observations of jellyfish in the Namibian Benguela. Mar. Ecol. Prog. Ser. 210, 55-66.

Clay, C.S., Horne, J.K. 1994. Acoustic models of fish: The Atlantic cod (Gadus morhua). J. Acoustc. Soc. Am. 96, 1661-1668.

Coetzee, J. 2000. Use of a shoal analysis and patch estimation system (SHAPES) to characterise sardine schools. Aquat. Living Resour. 13, 1-10.

Davis, C.S., Wiebe, P.H. 1985. Macrozooplankton biomass in a warm-core Gulf Stream ring: time series changes in size structure, taxonomic composition, and vertical distribution. 
J. Geophys. Res. 90, 8871-8882.

469 Demer, D.A., Berger, L., Bernasconi, M., Bethke, E., Boswell, K., Chu, D., Domokos, R., et al.

470 2015. Calibration of acoustic instruments. ICES Coop. Res. Rep. No. 326.133 pp.

471 De Robertis, A., McKelvey, D.R., Ressler, P.H. 2010. Development and application of an

472 empirical multifrequency method for backscatter classification. Can. J. Fish. Aquat. Sci.

$473 \quad 67,1459-1474$.

474 Edwards, J.L., Armstrong, F., Magurran, A.E., Pitcher, T.J. 1984. Herring, mackerel and

475 sprat Target Strength experiments with behavioural observations. Int. Counc. Explor. Sea

476 CM 1984/B:34, 1-23.

477 Foote, K.G. 1980. Importance of the swimbladder in acoustic scattering by fish: A comparison of 478 gadoid and mackeral target strengths. J. Acoust. Soc. Am. 67, 2084-2089.

479 Gauthier, S., Horne, J.K. 2004. Acoustic characteristics of forage fish species in the Gulf of $480 \quad$ Alaska and Bering Sea based on Kirchhoff-approximation models. Can. J. Fish. Aquat. $481 \quad$ Sci. 61, 1839-1850.

482 Greenlaw, C.F. 1979. Acoustical estimation of zooplankton populations. Limnol. Oceanogr. 24, $483 \quad 226-242$.

484 Henderson, M.J., Horne, J.K. 2007. Comparison of in situ, ex situ, and backscatter model 485 estimates of Pacific hake (Merluccius productus) target strength. Can. J. Fish. Aquat. Sci. 64, 1781-1794.

487 Herrmann, B. 2014. Effects of hypoxia on the distribution of jellyfish in Hood Canal and 488 potential influences on food web dynamics. Senior undergraduate thesis, University of $489 \quad$ Washington, 38pp.

490 Holliday, D.V., Pieper, R.E. 1980. Volume scattering strengths and zooplankton distributions at 
acoustic frequencies between 0.5 and 3 MHz. J. Acoust. Soc. Am. 67, 135-146.

492 Horne, J.K., Clay, C.S. 1998. Sonar systems and aquatic organisms: matching equipment and model parameters. Can. J. Fish. Aquat. Sci. 55, 1296-1306.

494 Horne, J.K. 2000. Acoustic approaches to remote species identification: a review. Fish. Oceanogr. 9, 356-371.

496 Jech, J.M., Michaels, W.L. 2006. A multifrequency method to classify and evaluate fisheries acoustic data. Can. J. Fish. Aquat. Sci. 63, 2225-2235.

498 Kang, M., Furusawa, M., Miyashita, K. 2002. Effective and accurate use of difference in mean 499 volume backscattering strength to identify fish and plankton. ICES J. Mar. Sci. 59, 794$500 \quad 804$.

501 Keister, J.E., Tuttle, L.B. 2013. Effects of bottom-layer hypoxia on spatial distributions and 502 community structure of mesozooplankton in a sub-estuary of Puget Sound, Washington, U.S.A. Limnol. Oceanogr. 58, 667-680.

504 Korneliussen, R.J., Ona, E. 2003. Synthetic echograms generated from the relative frequency 505 response. ICES J. Mar. Sci. 60, 636-640.

506 Lavaniegos, B.E., Ohman, M.D. 2007. Coherence of long-term variations of zooplankton in two sectors of the California Current System. Prog. Oceanogr. 75, 42-69.

508 Little, W.S., Copley, N.J. 2003. WHOI Silhouette Digitizer version 1.0 User's Guide. Woods $509 \quad$ Hole Oceanogr. Inst. Tech. Rep. 5, 1-63.

510 Mackas, D.L., Kieser, R., Saunders, M., Yelland, D.R., Brown, R.M., Moore, D.F. 1997. 511 Aggregation of euphausiids and Pacific hake (Merluccius productus) along the outer continental shelf off Vancouver Island. Can. J. Fish. Aquat. Sci. 54, 2080-2096.

513 MacLennan, D.N., Holliday, D.V. 1996. Fisheries and plankton acoustics: past, present, and 
future. ICES J. Mar. Sci. 53, 513-516.

515 Madureira, L.S.P., Everson, I., Murphy, E.J. 1993. Interpretation of acoustic data at two 516 frequencies to discriminate between Antarctic krill (Euphausia superba Dana) and other 517 scatterers. J. Plankton Res. 15, 787-802.

518 Mauchline, J. 1980. Measurement of body length of Euphausia superba Dana. BIOMASS $519 \quad$ Handbook No. 4, 4-9.

520 McClatchie, S., Thorne, R.E., Grimes, P., Hanchet, S. 2000. Ground truth and target 521 identification for fisheries acoustics. Fish. Res. 47, 173-191.

522 McKelvey, D.R., Wilson, C.D. 2006. Discriminant classification of fish and zooplankton 523 backscattering at 38 and $120 \mathrm{kHz}$. T. Am. Fish. Soc. 135, 488-499.

524 Moriarty, P.E., Andrews, K.S., Harvey, C.J., Kawase, M. 2012. Vertical and horizontal 525 movement patterns of scyphozoan jellyfish in a fjord-like estuary. Mar. Ecol. Prog. Ser. $526 \quad 455,1-12$.

527 Ona, E. 1990. Physiological factors causing natural variations in acoustic target strength of fish. $528 \quad$ J. Mar. Biol. Assoc. U. K. 70, 107-127.

529 Ona, E. 2001. Herring tilt angles through target tracking. In Herring: Expectations for a New 530 Millenium. Lowell Wakefield Fisheries Symposia Series, Fairbanks, Alaska, pp. 509531 519. Ed. By F. Funk, J. Blackburn, D. Hay, A.J. Oaul, R. Stephenson, R. Toresen, and D. $532 \quad$ Witherell.

533 Parker-Stetter, S.L., Horne, J.K., Langness, M.M. 2008. The influence of midwater hypoxia on 534 nekton vertical migration. ICES J. Mar. Sci. 66, 1296-1302.

535 Purcell, J.E., Brown, E.D., Stokesbury, K.D.E., Haldorson, L.H., Shirley, T.C. 2000.

536 Aggregations of the jellyfish Aurelia labiata: abundance, distribution, association with 

age-0 walleye pollock, and behaviors promoting aggregation in Prince William Sound, 538 Alaska, USA. Mar. Ecol. Prog. Ser. 195, 145-158.

539 Sato, M., Dower, J.F., Kunze, E., Dewey, R. 2013. Second-order seasonal variability in diel 540 vertical migration timing of euphausiids in a coastal inlet. Mar. Ecol. Prog. Ser. 480, 3954156.

542 Webber, M.K., Roff, J.C. 1995. Annual biomass and production of the oceanic copepod 543 community off Discovery Bay, Jamaica. Mar. Biol. 123, 481-495.

544 Williams, R., Robins, D. 1979. Caloric, ash, carbon and nitrogen content in relation to length and 545 dry weight of Parathemisto gaudichaudi (Amphipoda: Hyperiidea) in the north east $546 \quad$ Atlantic Ocean. Mar. Biol. 52, 247-252. 


\section{Figure captions}

548

549 Figure 1. Schematic illustrating the acoustic classification of coexisting taxa, including removal

550 of aggregations and single targets in raw data $\left(S_{v}\right)$ and then application of $\triangle \mathrm{MVBS}$ on averaged

551 data (MVBS).

552

553 Figure 2. Histograms of (a) $\triangle \mathrm{MVBS}_{200-38}$ identified as fish (herring and hake combined) and

554 zooplankton, and (b) $\triangle \mathrm{MVBS}_{120-38}$ identified as herring and hake for 20-ping $\times 2$-m analysis

555 cells. Dotted lines indicate the values used to separate fish and zooplankton at $\Delta \mathrm{MVBS}_{200-38}=$ $5562.0 \mathrm{~dB}$, and herring and hake at $\Delta \mathrm{MVBS}_{120-38}=-4.8 \mathrm{~dB}$. 
557 Table 1. Parameters used for the school detection module in Echoview. Different values were

558 used for detecting herring ( $S_{v}$ herring aggregation $)$ and other aggregations $\left(S_{v}\right.$ other aggregation $)$. Values for

559 maximum horizontal linking distance were adjusted based on sampling frequencies, with $3 \mathrm{~m}$ for

560 data sampled at $2 \mathrm{~Hz}$ and $10 \mathrm{~m}$ at $0.5 \mathrm{~Hz}$.

561

\begin{tabular}{lcc}
\hline \multirow{2}{*}{ Parameters } & \multicolumn{2}{c}{ Values } \\
\cline { 2 - 3 } & herring aggregation & other aggregation \\
\hline Minimum threshold $\left(\mathrm{dB}\right.$ re $\left.1 \mathrm{~m}^{-1}\right)$ & -60.0 & -70.0 \\
Minimum total school length $(\mathrm{m})$ & 5.0 & 4.5 \\
Minimum total school height $(\mathrm{m})$ & 2.0 & 0.5 \\
Minimum candidate length $(\mathrm{m})$ & 5.0 & 4.5 \\
Maximum candidate length $(\mathrm{m})$ & 2.0 & 0.5 \\
Maximum vertical linking distance $(\mathrm{m})$ & 0.2 & 0.2 \\
Maximum horizontal linking distance $(\mathrm{m})$ & $3.0(10.0)$ & $3.0(10.0)$ \\
\hline
\end{tabular}


563 Table 2. Parameters used for single target detection in Echoview.

564

\begin{tabular}{lc}
\hline Parameters & Values \\
\hline TS threshold $\left(\mathrm{dB}\right.$ re $\left.1 \mathrm{~m}^{2}\right)$ & -80 \\
Pulse length determination level $(\mathrm{dB})$ & 12 \\
Minimum normalized pulse length & 0.8 \\
Maximum normalized pulse length & 2.0 \\
Maximum beam compensation (dB) & 12 \\
Maximum standard deviation of minor-axis angles $\left(^{\circ}\right)$ & 3.0 \\
Maximum standard deviation of major-axis angles $\left(^{\circ}\right)$ & 3.0 \\
\hline
\end{tabular}

565 
566 Table 3. Summary of $\triangle$ MVBS values of the representative samples.

567

\begin{tabular}{lccc}
\hline & \multicolumn{3}{c}{ Mean \pm standard deviation $(\mathrm{dB})$} \\
\cline { 2 - 4 } & Pacific Herring & Pacific Hake & Zooplankton \\
\hline Number of trawls & 5 & 2 & 10 \\
Number of analysis cells & 1074 & 270 & 2340 \\
$\Delta$ MVBS $_{70-38}$ & $-1.45 \pm 1.84$ & $-4.27 \pm 2.12$ & $3.61 \pm 2.59$ \\
$\Delta$ MVBS $_{120-38}$ & $-2.51 \pm 2.21$ & $-7.12 \pm 2.22$ & $9.93 \pm 2.82$ \\
$\Delta$ MVBS $_{200-38}$ & $-4.55 \pm 2.04$ & $-7.95 \pm 2.09$ & $12.21 \pm 2.97$ \\
$\Delta$ MVBS $_{120-70}$ & $-1.07 \pm 1.09$ & $-2.85 \pm 1.83$ & $6.32 \pm 1.40$ \\
$\Delta$ MVBS $_{200-70}$ & $-3.11 \pm 1.19$ & $-3.68 \pm 2.01$ & $8.60 \pm 1.97$ \\
$\Delta$ MVBS $_{200-120}$ & $-2.04 \pm 1.02$ & $-0.83 \pm 1.44$ & $2.28 \pm 1.42$ \\
\hline
\end{tabular}




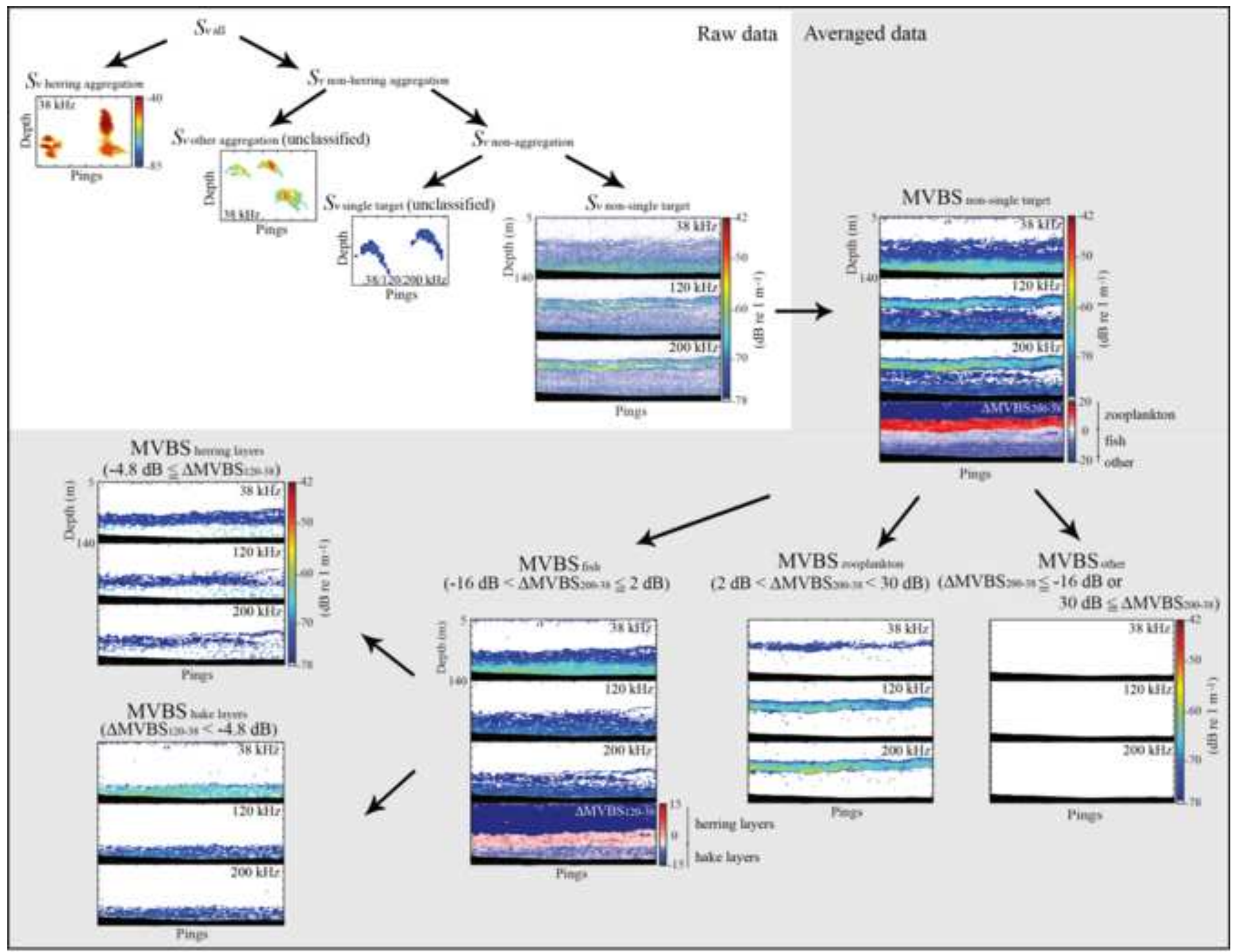

Figure I 

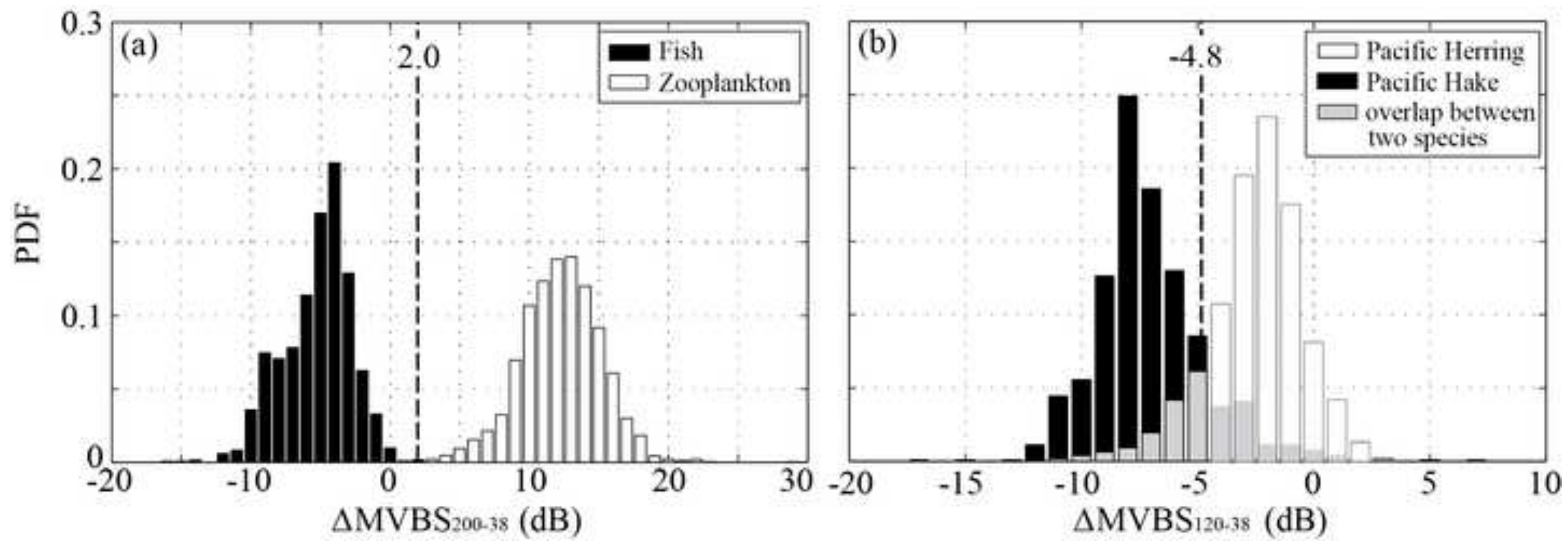